\title{
Percutaneous Transhepatically Assisted Surgical Repair of a Complete Bile Duct Dissection Due to Laparoscopic Cholecystectomy
}

The introduction of laparoscopic cholecystectomy was associated with an increased rate of biliary complications such as leakages and strictures [1]. While most of these can be successfully treated endoscopically or with percutaneous transhepatic biliary drainage (PTBD) [2,3], complete dissection of the common bile duct requires surgical repair in virtually all cases [4]. We report here the case of a 31year-old man who presented 3 days after laparoscopic cholecystectomy with cholestasis (alkaline phosphatase $476 \mathrm{U} / \mathrm{l}$, normal range 40-129; bilirubin $8.4 \mathrm{mg} /$ $\mathrm{dl} \leq 1.2$ ). Endoscopic retrograde cholangiography showed complete blockage of contrast in the distal part of the common bile duct (Figure 1), which was not traversable with various guide wires. PTBD was therefore carried out, showing dilated intrahepatic bile ducts and complete ductal obstruction of the common hepatic duct, representing the proximal end of a complete dissection (Figure 2 ). The distance between the two obstructed ducts was estimated to be $1.5 \mathrm{~cm}$, with clips being visible in the area. The PTBD procedure was terminated with the insertion of a pigtail prosthesis for drainage, and the patient was referred for surgery.

Intraoperatively, after the removal of two clips, a guide wire was inserted via the percutaneous transhepatic tract; however, the duodenum could not be reached, as the wire passed freely into the abdominal cavity. With manual assistance from the surgeon, the guide wire was then inserted into the dissected distal bile duct, finally leading to the insertion of a $10-\mathrm{Fr}$ percutaneous pigtail prosthesis with its tip in the duodenum. End-to-end suturing of the bile duct was carried out, and the defect was also covered with tissue patches obtained from the omentum.

Two weeks later, the pigtail PTBD was exchanged for a 12-Fr Yamakawa-type prosthesis. During a further exchange, a stricture in this area was observed (Figure 3), which on cholangioscopy had the appearance of a circumscribed tissue growth. La-

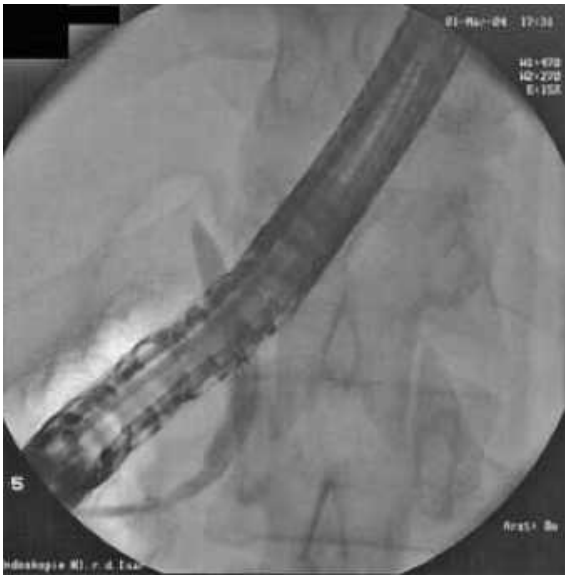

Figure 1 Endoscopic retrograde cholangiography. Complete blockage of the contrast is seen in the distal common bile duct.

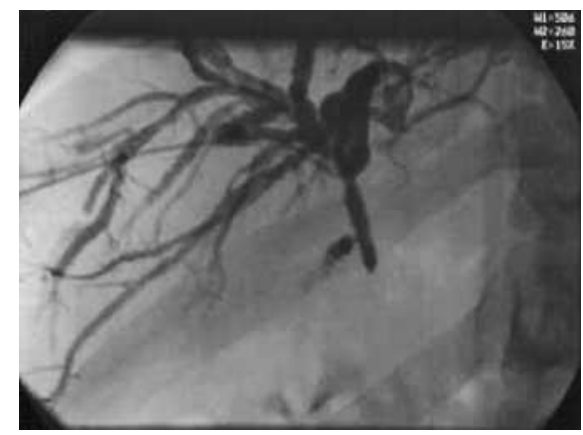

Figure 2 Percutaneous transhepatic biliary drainage. The biliary system proximal to the dissection is seen.

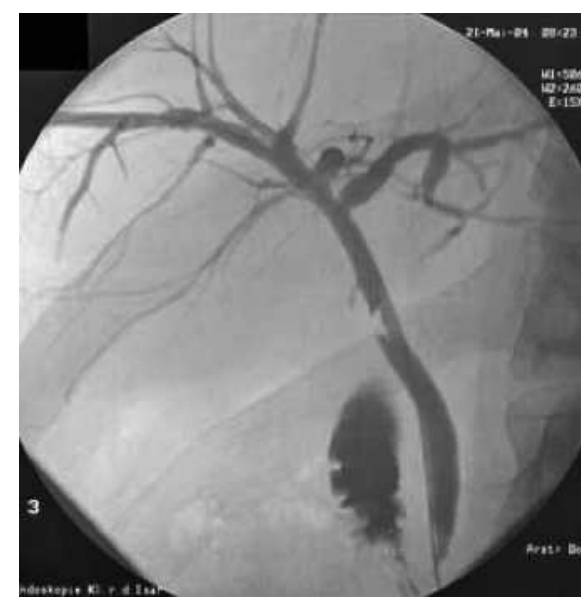

Figure 3 Endoscopic retrograde cholangiography, showing the situation several weeks after the intervention. ter on, the percutaneous drain was replaced with two endoscopically placed 10 -Fr stents. The internal drain was to be left in place for a total of 1 year. It remains to be seen whether this combination treatment will ultimately be successful clinically, potentially providing an alternative to surgical biliary/digestive anastomoses, particularly in young patients.

\section{P. Born', T. Rösch', M. Stangl ${ }^{\mathbf{1}}$}

${ }^{1}$ Dept. of Internal Medicine II,

Rechts der Isar Hospital, Technical

University of Munich, Munich, Germany 2 Dept. of Surgery,

Rechts der Isar Hospital, Technical

University of Munich, Munich, Germany.

\section{References}

\section{${ }^{1}$ Siewert JR, Ungeheuer A, Feussner $\mathrm{H}$. Gallenwegsläsionen bei laparoskopi- scher Cholecystektomie. Chirurg 194; 64: $748-757$ \\ ${ }^{2}$ Mutignani M, Tringali A, Costamagna G. Therapeutic biliary endoscopy. Endos- copy 2004; 36: 147 - 159 \\ ${ }^{3}$ Born P, Rösch T, Brühl K et al. Long-term results of endoscopic and percutaneous transhepatic treatment of benign bili- ary strictures. Endoscopy 1999; 31: $725-731$ \\ ${ }^{4}$ Petzold V, Rösch T, Born P. Kombiniertes endoskopisches und transhepatisch- perkutanes Vorgehen bei postoperati- ver kompletter Gallengangsokklusion. Dtsch Med Wochenschr 2001; 126 : $1197-1200$}

\section{Corresponding Author}

\section{P. Born, M.D.}

II. Medizinische Klinik

Klinikum rechts der Isar

Ismaningerstraße 22

81675 München

Germany

Fax: +49-89-4140-4905

E-mail: peter.born@lrz.tum.de 